\title{
Article \\ Increasing the Efficiency of Canola and Soybean GMO Detection and Quantification Using Multiplex Droplet Digital PCR
}

\author{
Tigst Demeke *, Sung-Jong Lee (D) and Monika Eng
}

Citation: Demeke, T.; Lee, S.-J.; Eng, M. Increasing the Efficiency of Canola and Soybean GMO Detection and Quantification Using Multiplex Droplet Digital PCR. Biology 2022, 11, 201. https://doi.org/10.3390/ biology11020201

Academic Editor: Pierre Devaux

Received: 17 December 2021 Accepted: 24 January 2022 Published: 27 January 2022

Publisher's Note: MDPI stays neutral with regard to jurisdictional claims in published maps and institutional affiliations.

Copyright: @ 2022 Crown Copyright This article is an open access article distributed under the terms and conditions of the Creative Commons Attribution (CC BY) license (https:// creativecommons.org/licenses/by/ $4.0 /)$.
Grain Research Laboratory, Canadian Grain Commission, Winnipeg, MB R3C 3G8, Canada; sung-jong.lee@grainscanada.gc.ca (S.-J.L.); monika.eng@grainscanada.gc.ca (M.E.)

* Correspondence: tigst.demeke@grainscanada.gc.ca; Tel.: +1-204-984-4582

Simple Summary: Digital PCR (dPCR) technology has been used for absolute quantification of genetically modified (GM) events. Duplex dPCR consisting of a target gene and a reference gene is mostly used for absolute quantification of GM events. We investigated the feasibility of absolute quantification of two, three, and four GM canola and soybean events at the same time using the QX200 Droplet Digital PCR (ddPCR) system. Adjustments of the probe concentrations and labels for some of the assays were needed for successful multiplex ddPCR. Absolute quantification of GM canola and soybean events was achieved for duplex, triplex, and tetraplex ddPCR at $0.1 \%, 1 \%$, and $5 \%$ concentrations.

\begin{abstract}
The number of genetically modified (GM) events for canola, maize, and soybean has been steadily increasing. Real-time PCR is widely used for the detection and quantification of individual GM events. Digital PCR (dPCR) has also been used for absolute quantification of GM events. A duplex dPCR assay consisting of one reference gene and one GM event has been carried out in most cases. The detection of more than one GM event in a single assay will increase the efficiency of dPCR. The feasibility of detection and quantification of two, three, and four GM canola and soybean events at the same time was investigated at $0.1 \%, 1 \%$, and 5\% levels using the QX200 Droplet Digital PCR (ddPCR) system. The reference gene assay was carried out on the same plate but in different wells. For some of the assays, optimization of the probe concentrations and labels was needed for successful ddPCR. Results close to the expected result were achieved for duplex, triplex, and tetraplex ddPCR assays for GM canola events. Similar ddPCR results were also achieved for some GM soybean events with some exceptions. Overall, absolute quantification of up to four GM events at the same time improves the efficiency of GM detection.
\end{abstract}

Keywords: droplet digital PCR (ddPCR); multiplex; GM event; canola; soybean; detection; duplex; triplex; tetraplex

\section{Introduction}

The number of genetically modified (GM) events has been increasing since the start of commercialization of GM crops in the mid-1990s [1]. Many countries have a regulatory approval process for new GM events and effective detection methods are required for monitoring [2-4]. The enforcement of labeling laws for GM grains and derived products also necessitates effective detection methods. The main reason for enforcement is because of consumers' rights to know what is in their food. New breeding technologies, such as CRISPR-Cas9, are also being used for crop improvement and information about genetic modification is required if there is a need for monitoring [5]. Real-time qualitative and quantitative PCR assays have been widely used for the detection and quantitative analysis of GM events [6-8]. However, the real-time PCR assay relies on the availability of certified reference materials and use of appropriate standard curves. Two calibration curves (for 
transgene and endogene) are used for real-time PCR to calculate the amount of target DNA present in the unknown sample [9]. The minimum required performance limit (MRPL), which is the lowest level of GM material required for the validation of quantitative methods, has been set by European Union Reference Laboratory at 0.1\% [10].

At the moment, digital PCR (dPCR) is being used by many laboratories for the detection and quantification of GM events [11,12]. Digital PCR is more convenient than real-time PCR since it does not require a standard curve. Collaborative studies have shown high reproducibility of dPCR assays [13,14]. An inter-laboratory dPCR study comprising seven independent laboratories showed less than $4.5 \%$ reproducibility relative standard deviation for a high GC-rich reference material [13]. dPCR assays have also been reported to be less sensitive to inhibitors in the DNA samples compared with real-time quantitative PCR assays [15-17]. However, ethanol has been reported to affect the stability of droplets for dPCR [15].

Digital PCR is used for absolute quantification of target nucleic acids in a GM sample. Droplet-based and chip-based APCR instruments are used for the detection of GM events and other applications [18]. The PCR solution is partitioned into different sub-reactions or droplets. The regular PCR instrument is used to amplify the individual sub-reactions and Poisson statistics are used to determine the concentration of the target sequence [19]. The use of primers and probes for one target and one reference gene in the same PCR (duplex $\mathrm{dPCR}$ ) has been routinely used for the detection and quantification of GM events [20-22]. However, the detection and quantification of one GM event at a time is not efficient. The Bio-Rad QX200 has two fluorescence filters, which is suitable for performing duplex droplet digital PCR (ddPCR). Optimization of the probe concentrations and ratios was conducted for absolute quantification of more than two targets for spinal muscular atrophy [23]. The detection of four GM maize events at the same time using ddPCR has been reported [24]. Two 4-plex assays consisting of $4 \mathrm{GM}$ events for 1 set and $3 \mathrm{GM}$ events and an endogene for the second set were used for the multiplex ddPCR maize assay. The basic principles of multiplexing with dPCR have also been documented [25].

In general, the wide applicability of multiplex dPCR for the detection of GM events has not been investigated. A successful multiplex dPCR assay for GM events will enhance the efficiency of detection and save resources. The objective of this study was to assess the feasibility of the quantification of two, three, and four GM canola and soybean events at the same time using the QX200 ddPCR system. Our plan was to investigate whether the multiplex ddPCR works for two GM events initially and then proceed to three and four GM events. The adoption rate for biotech canola and soybean in Canada was reported to be $92.5 \%$ in 2018 [26]. The development of efficient detection methods for discontinued and new GM canola and soybean events is important for monitoring.

\section{Materials and Methods}

\subsection{Sources of Seeds and Reference Materials}

The seeds and reference materials used for the canola ddPCR assay were Legend (nonGM canola, certified seed), Conquest (breeder seed-GT73 GM event-Glyphosate herbicide tolerance), Innovator (breeder seed-HCN92 GM event-Glufosinate herbicide tolerance), Armor BX (breeder seed-OXY235 GM event-Oxynil herbicide tolerance), and AOCS 1011-A (certified reference material, CRM-MON88302 GM event-Glyphosate herbicide tolerance). The seeds of Legend, Conquest, and Innovator were obtained from Oilseeds Program of the Grain Research Laboratory.

The seeds and reference materials used for soybean ddPCR assay were Colby (non-GM soybean variety), PS 2295 LL (certified seed-A2704 GM event-Glufosinate herbicide tolerance), ERM-BF426d (CRM-DP305423 GM event-Sulfonylurea herbicide, modified oil/fatty acid), AOCS-0906B2 (CRM-MON89788 GM event-Glyphosate herbicide tolerance), and ERM-BF437-B (CRM-DAS81419 GM event-Glufosinate herbicide tolerance, Lepidopteran insect resistance). Certified seeds of Colby were obtained from WG Thompson \& Sons 
(Granton, ON, Canada) and certified seeds of PS 2295 LL were obtained from Bayer Crop Science. All the canola and soybean varieties were grown in Canada.

\subsection{DNA Extraction and Quantification}

DNA was extracted using a DNeasy mericon Food kit (Qiagen Life Sciences, LLC, Louisville, KY, USA). Agarose gel-electrophoresis (1.2\%) was used to check the quality of DNA. 1X TAE (Tris-Acetate-EDTA) buffer containing $0.44 \mathrm{mM}$ GelRed dye (Biotium, Cedarlane Laboratories, Hornby, Ontario-sourced from Fremont, CA, USA) was used for gel-electrophoresis. The Pico Green ${ }^{\circledR}$ assay (Molecular Probes, Eugene, OR, USA) was used to measure the amount of DNA and $\lambda$ DNA was used to generate a calibration curve. The Pico Green ${ }^{\circledR}$ dsDNA reagent was added to diluted DNA in a 96-well plate. A SpectraMax M5 Microplate Reader (Molecular Devices, Toronto, ON, Canada-sourced from San Jose, CA, USA) was used to measure the fluorescence in duplicates. In total, $100 \mathrm{ng}$ of DNA were used for all ddPCR experiments. Then, $0.1 \%, 1 \%$, and 5\% GM samples were prepared by mixing non-GM and GM DNA. A control without GM DNA was included for the experiments. A DNA mixture consisting of the different GM events was prepared for duplex, triplex, and tetraplex ddPCR. An example of how the DNA mixture was prepared is provided in the Supplementary Materials.

\subsection{Droplet Digital PCR}

A Bio-Rad QX200 instrument was used for ddPCR as described by Demeke et al. [27]. The event-specific primer and probe DNA sequences used for the experiments are shown in Table 1. The canola and soybean GM events were chosen based on in-house validation work done and successful participation in proficiency test programs. The primer and probe DNA sequences for the single copy reference genes used were FatA(A) for canola [28] and Lectin for soybean [29]. Canola and soybean GM events were assessed for the multiplex ddPCR. The reference gene assay was run with the ddPCR on the same plate separately so that more target genes could be assessed for the multiplex ddPCR. In total, 3 replications of the reference gene assay $(\operatorname{FatA}(\mathrm{A})$ or Lectin) were carried out for each of the $3 \mathrm{GM}$ concentrations determined $(0.1 \%, 1 \%$, and $5 \%)$. The average number of reference droplets was used for absolute quantification of each GM event. The concentrations of the primers and probes used for duplex, triplex, and tetraplex ddPCR are shown in Supplementary Tables S1-S3, respectively.

Table 1. Primer and probe DNA sequences used for absolute quantification of GM canola and soybean events.

\begin{tabular}{|c|c|c|c|c|}
\hline Crop & Event Name & Primer/Probe Name & DNA Sequences $\left(5^{\prime}\right.$ to $\left.3^{\prime}\right)$ & Amplicon Length (bp) \\
\hline \multirow[t]{15}{*}{ CANOLA } & \multirow[t]{3}{*}{ GT73 } & RT73-1 & CCA TAT TGA CCA TCA TAC TCA TTG CT & \multirow[t]{3}{*}{108} \\
\hline & & RT73-2 & GCT TAT ACG AAG GCA AGA AAA GGA & \\
\hline & & RT73 (P) & $\begin{array}{c}\text { TTC CCG GAC ATG AAG ATC ATC CTC } \\
\text { CTT-BHQ1 }\end{array}$ & \\
\hline & \multirow[t]{3}{*}{ OXY235 } & Oxy RG & GAT AGA TGG TGG TGT GAG TCT TGT & \multirow[t]{3}{*}{124} \\
\hline & & OXY RV & CCT AAC TTT TGG TGT GAT GAT GCT & \\
\hline & & Oxy RP & TGC CAT CAG CTG ACA CGC CGT GC-BHQ1 & \\
\hline & \multirow[t]{3}{*}{ HCN92 } & MDB685 & GTT GCG GTT CTG TCA GTT CC & \multirow[t]{3}{*}{95} \\
\hline & & KVM180 & CGA CCG GCG CTG ATA TAT GA & \\
\hline & & TM029 & TCC CGC GTC ATC GGC GG-BHQ1 & \\
\hline & \multirow[t]{3}{*}{ MON88302 } & $88302 \mathrm{QF}$ & TCC TTG AAC CTT ATT TTA TAG TGC ACA & \multirow[t]{3}{*}{101} \\
\hline & & 88302QR & TCA GAT TGT CGT TTC CCG CCT TCA & \\
\hline & & 88302QP & $\begin{array}{l}\text { TAG TCA TCA TGT TGT ACC ACT TCA AAC } \\
\text { ACT-BHQ1 }\end{array}$ & \\
\hline & \multirow[t]{3}{*}{ FatA(A) } & 09-0-2824-F & ACA GAT GAA GTT CGG GAC GAG TAC & \multirow[t]{3}{*}{84} \\
\hline & & 09-0-2825-R & CAG GTT GAG ATC CAC ATG CTT AAA TAT & \\
\hline & & 09-QP-87-P & AAG AAG AAT CAT CAT GCT TC-BHQ1 & \\
\hline
\end{tabular}


Table 1. Cont.

\begin{tabular}{|c|c|c|c|c|}
\hline Crop & Event Name & Primer/Probe Name & DNA Sequences $\left(5^{\prime}\right.$ to $\left.3^{\prime}\right)$ & Amplicon Length (bp) \\
\hline \multirow[t]{15}{*}{ SOYBEAN } & \multirow[t]{3}{*}{ DP305423 } & DP305 F1 & CGT GTT CTC TTT TTG GCT AGC & \multirow[t]{3}{*}{93} \\
\hline & & DP305 R5 & $\begin{array}{l}\text { GTG ACC AAT GAA TAC ATA ACA CAA } \\
\text { ACT A }\end{array}$ & \\
\hline & & DP305423 P & $\begin{array}{c}\text { TGA CAC AAA TGA TTT TCA TAC AAA } \\
\text { AGT CGA GA-BHQ1 }\end{array}$ & \\
\hline & \multirow[t]{3}{*}{ A2704 } & KVM175 & GCA AAA AAG CGG TTA GCT CCT & \multirow[t]{3}{*}{74} \\
\hline & & SMO 001 & ATT CAG GCT GCG CAA CTG TT & \\
\hline & & TM021 & CGG TCC TCC GAT CGC CCT TCC-BHQ1 & \\
\hline & \multirow[t]{3}{*}{ MON89788 } & MON89788 F & TCC CGC TCT AGC GCT TCA AT & \multirow[t]{3}{*}{139} \\
\hline & & MON89788 R & TCG AGC AGG ACC TGC AGA A & \\
\hline & & MON89788 P & $\begin{array}{c}\text { CTG AAG GCG GGA AAC GAC AAT } \\
\text { CTG-BHQ1 }\end{array}$ & \\
\hline & \multirow[t]{3}{*}{ DAS81419 } & DAS81419 F2 & $\begin{array}{c}\text { TCT AGC TAT ATT TAG CAC TTG ATA TTC } \\
\text { AT }\end{array}$ & \multirow[t]{3}{*}{105} \\
\hline & & DAS81419 R1 & GCT TCA AGA TCC CAA CTT GCG & \\
\hline & & DAS81419 P3 & $\begin{array}{c}\text { ATC AAC AGG CAC CGA TGC GCA } \\
\text { CCG-BHQ1 }\end{array}$ & \\
\hline & \multirow{3}{*}{ Lectin1 } & lec-F & CCA GCT TCG CCG CTT CCT TC & \multirow[t]{3}{*}{74} \\
\hline & & lec-R & GAA GGC AAG CCC ATC TGC AAG CC & \\
\hline & & lec-P & $\begin{array}{c}\text { CTT CAC CTT CTA TGC CCC TGA } \\
\text { CAC-BHQ1 }\end{array}$ & \\
\hline
\end{tabular}

Reporter dyes used are shown in the Supplementary Materials. FatA(A) and Lectin1 are the reference gene primers and probes used for canola and soybean, respectively.

QuantaSoft 1.7.4.0917 and automatic threshold were used for conducting the ddPCR assays. QX Manager Software (version 1.2) was used for analyzing tetraplex ddPCR assays.

\section{Results and Discussion}

\subsection{Optimization of the Probe Concentrations}

The QX200 ddPCR system has two fluorescence filters and it is a challenge to successfully run multiplex ddPCR involving more than two targets. Optimization of the probe concentrations is required for successful multiplex ddPCR consisting of more than two targets [24]. The primer and probe concentrations used for the ddPCR assays in this study were based on published information for real-time event-specific PCR assays [30,31] and in-house validation. The forward and reverse primer concentrations for 7 of the 8 target genes for ddPCR were kept at $0.4 \mu \mathrm{M}$. For the DP305423 soybean event, forward and reverse primer concentrations of $0.8 \mu \mathrm{M}$ and $0.5 \mu \mathrm{M}$ were used, respectively [32]. For probe optimization, all four GM events were run individually using FAM and HEX probe dyes in triplicates to determine the signal intensity and establish the cluster location. Based on the results, the probes for the GM events to be labeled with either FAM or HEX were determined. Then, all four GM events were run together to assess the pattern and separation of clusters. After that, the probe concentrations were adjusted in order to obtain clear separation of the clusters. The concentrations of primers and probes and the probe labels used for duplex, triplex, and tetraplex ddPCR are shown in Supplementary Tables S1-S3. Increased probe concentrations were used for some of the events for triplex and tetraplex ddPCR compared to duplex ddPCR. Mixtures of equal amounts of FAM- and HEX-labeled probes were used for MON88302 and DP305423 GM events in order to obtain the third position for triplex ddPCR. Distinct separation of all positive droplet clusters was not obtained before optimization of the probe concentrations (Figure 1).

\subsection{Detection of Two GM Events (Duplex ddPCR)}

Three pairs of GM canola events were assessed for the detection of $0.1 \%, 1 \%$, and $5 \%$ spiked samples (Table 2). Close to the expected results were achieved for the HCN92 and GT73, HCN92 and MON88302, and GT73 and MON88302 duplex ddPCR assays. Three 
pairs of GM soybean events (A2704 and DP305423, A2704 and MON89788, and DP305423 and MON89788) were also assessed for three concentrations of spiked DNA samples (Table 2). For the soybean duplex ddPCR assay, some of the results for the $0.1 \%$ and $1 \%$ samples were higher than the expected values. The reference gene assay carried out in different wells of the same plate to that of the duplex ddPCR assay was suitable for absolute quantification. An example of the distribution of droplets that formed for duplex canola ddPCR is depicted in Figure 2. Quantifying two GM events at the same time is an improvement of the routine duplex ddPCR assay, which consists of one GM event and the reference gene.

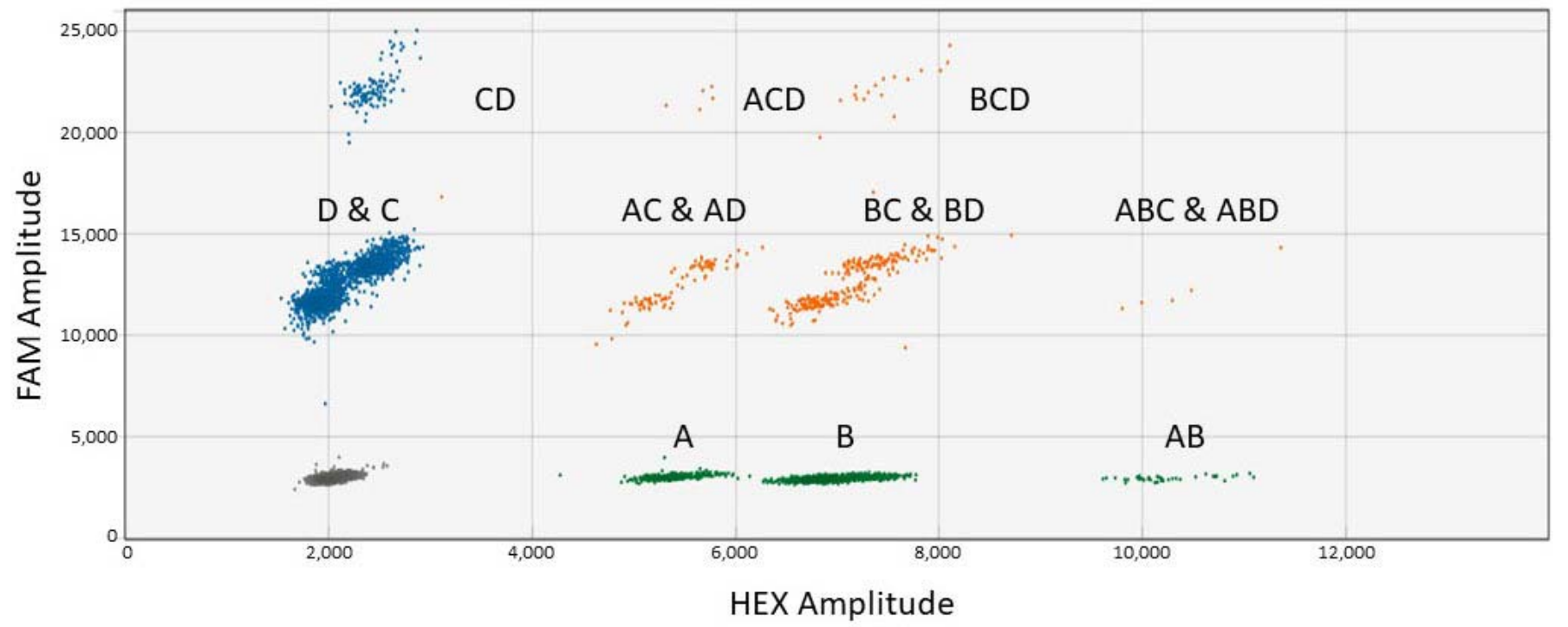

Figure 1. Droplet clusters generated for the non-optimized soybean tetraplex ddPCR assay (twodimensional view). $\mathrm{A}=\mathrm{DP} 305423$ event (HEX); $\mathrm{B}=$ DAS81419 event (HEX); $\mathrm{C}=$ MON89788 event $(\mathrm{FAM})$; and $\mathrm{D}=\mathrm{A} 2704$ event $(\mathrm{FAM})$. The dark cluster represents negative droplets.

Table 2. Experimental results for duplex ddPCR assays for GM canola and soybean events.

\begin{tabular}{cccccc}
\hline \multirow{2}{*}{ Crop } & \multirow{2}{*}{ Duplex Events } & \multirow{2}{*}{ Event } & \multicolumn{3}{c}{ Experimental Results $^{\mathbf{a}}$} \\
\cline { 4 - 6 } & & & $\mathbf{0 . 1 \%}$ & $\mathbf{1 \%}$ & $\mathbf{5 \%}$ \\
\hline Canola & HCN92 and GT73 & HCN92 & $0.08 \pm 0.01$ & $1.12 \pm 0.07$ & $5.20 \pm 0.48$ \\
& & GT73 & $0.08 \pm 0.03$ & $1.00 \pm 0.12$ & $5.30 \pm 0.40$ \\
& HCN92 and & HCN92 & $0.07 \pm 0.01$ & $0.94 \pm 0.08$ & $4.53 \pm 0.42$ \\
& MON88302 & MON88302 & $0.10 \pm 0.01$ & $1.06 \pm 0.06$ & $5.10 \pm 0.22$ \\
& GT73 and MON88302 & GT73 & $0.08 \pm 0.03$ & $0.94 \pm 0.10$ & $4.55 \pm 0.25$ \\
& & MON88302 & $0.08 \pm 0.02$ & $0.93 \pm 0.07$ & $5.10 \pm 0.25$ \\
& \multirow{2}{*}{ A2704 and DP305423 } & A2704 & $0.16 \pm 0.02$ & $1.26 \pm 0.10$ & $4.69 \pm 0.68$ \\
& & DP305423 & $0.18 \pm 0.06$ & $1.56 \pm 0.07$ & $5.57 \pm 0.65$ \\
& A2704 and MON89788 & A2704 & $0.13 \pm 0.03$ & $1.16 \pm 0.08$ & $4.49 \pm 0.65$ \\
& & MON89788 & $0.15 \pm 0.02$ & $1.35 \pm 0.05$ & $4.93 \pm 0.69$ \\
& DP305423 and & DP305423 & $0.15 \pm 0.03$ & $1.50 \pm 0.02$ & $5.65 \pm 0.24$ \\
& MON89788 & MON89788 & $0.12 \pm 0.00$ & $1.33 \pm 0.03$ & $4.83 \pm 0.14$ \\
\hline
\end{tabular}

a Average of three replications \pm standard deviation. 

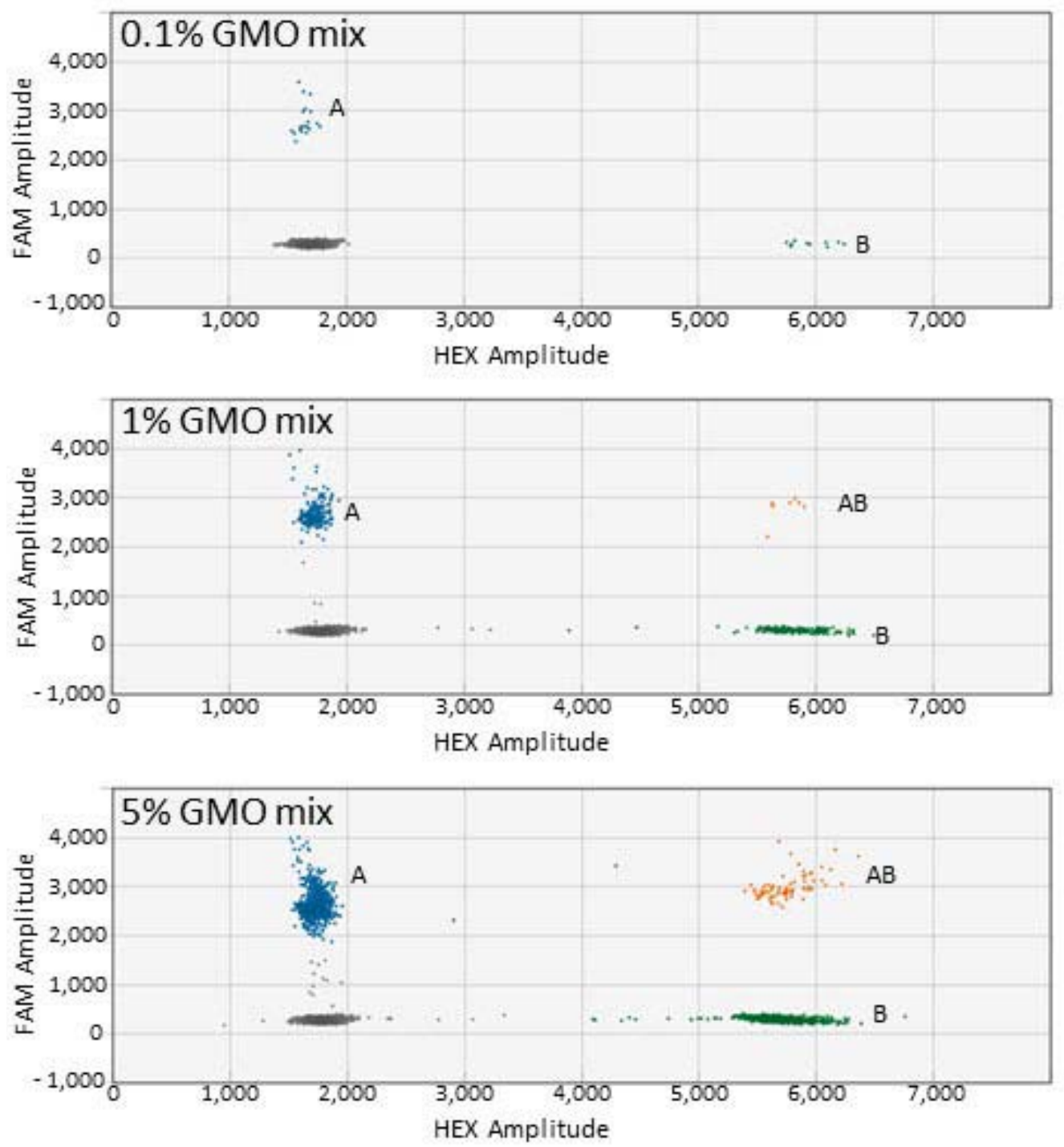

Figure 2. Droplet clusters generated for the duplex canola ddPCR assay. $A=H C N 92$ (FAM); $\mathrm{B}=$ GT73 (HEX); and AB = Contains both HCN92 and GT73 droplets. The dark cluster represents negative droplets.

\subsection{Detection of Three GM Events (Triplex ddPCR)}

Spiked DNA samples containing three GM events were assessed at three concentrations (Table 3). The first triplex ddPCR canola assay consisted of HCN92, GT73, and MON88302 events while the second triplex ddPCR canola assay consisted of OXY235, GT73, and MON88302 events. Close to the expected values were achieved for the triplex canola ddPCR assays. An example of the distribution of droplets for the triplex ddPCR canola assay is shown in Figure 3. Improved resolution of the different droplets was observed at the highest concentration (5\%). The seven positive clusters and the negative cluster were well separated. The triplex ddPCR soybean assay consisted of A2704, DP305423, and MON89788 for one set and A2704, DAS81419, and MON89788 for the second set (Table 3). Close to the expected results were achieved, with the exception of DP305423 at $0.1 \%$. 
Table 3. Experimental results for triplex ddPCR assays for GM canola and soybean events.

\begin{tabular}{|c|c|c|c|c|c|}
\hline \multirow{2}{*}{ Crop } & \multirow{2}{*}{ Triplex Events } & \multirow{2}{*}{ Event } & \multicolumn{3}{|c|}{ Experimental Results ${ }^{a}$} \\
\hline & & & $0.1 \%$ & $1 \%$ & $5 \%$ \\
\hline \multirow[t]{3}{*}{ Canola } & \multirow{3}{*}{$\begin{array}{l}\text { HCN92, GT73, } \\
\text { and MON88302 }\end{array}$} & HCN92 & $0.10 \pm 0.03$ & $1.09 \pm 0.08$ & $5.15 \pm 0.30$ \\
\hline & & GT73 & $0.12 \pm 0.01$ & $1.07 \pm 0.05$ & $4.99 \pm 0.12$ \\
\hline & & MON88302 & $0.11 \pm 0.01$ & $1.05 \pm 0.03$ & $5.09 \pm 0.32$ \\
\hline \multirow[t]{3}{*}{ Canola } & \multirow{3}{*}{$\begin{array}{c}\text { OXY235, GT73, and } \\
\text { MON88302 }\end{array}$} & OXY235 & $0.13 \pm 0.01$ & $1.38 \pm 0.07$ & $6.27 \pm 0.19$ \\
\hline & & GT73 & $0.12 \pm 0.01$ & $1.17 \pm 0.02$ & $5.31 \pm 0.06$ \\
\hline & & MON88302 & $0.12 \pm 0.01$ & $1.12 \pm 0.05$ & $5.22 \pm 0.18$ \\
\hline \multirow[t]{3}{*}{ Soybean } & \multirow{3}{*}{$\begin{array}{l}\text { A2704, DP305423, } \\
\text { and MON89788 }\end{array}$} & A2704 & $0.11 \pm 0.03$ & $0.94 \pm 0.09$ & $3.91 \pm 0.10$ \\
\hline & & DP305423 & $0.17 \pm 0.05$ & $1.22 \pm 0.04$ & $5.21 \pm 0.32$ \\
\hline & & MON89788 & $0.12 \pm 0.02$ & $1.01 \pm 0.14$ & $4.51 \pm 0.33$ \\
\hline \multirow[t]{3}{*}{ Soybean } & \multirow{3}{*}{$\begin{array}{l}\text { A2704, DAS81419, } \\
\text { and MON89788 }\end{array}$} & A2704 & $0.10 \pm 0.05$ & $1.03 \pm 0.04$ & $4.90 \pm 0.17$ \\
\hline & & DAS81419 & $0.14 \pm 0.03$ & $1.35 \pm 0.06$ & $6.20 \pm 0.17$ \\
\hline & & MON89788 & $0.10 \pm 0.01$ & $1.15 \pm 0.05$ & $5.41 \pm 0.22$ \\
\hline
\end{tabular}

${ }^{a}$ Average of three replications \pm standard deviation.
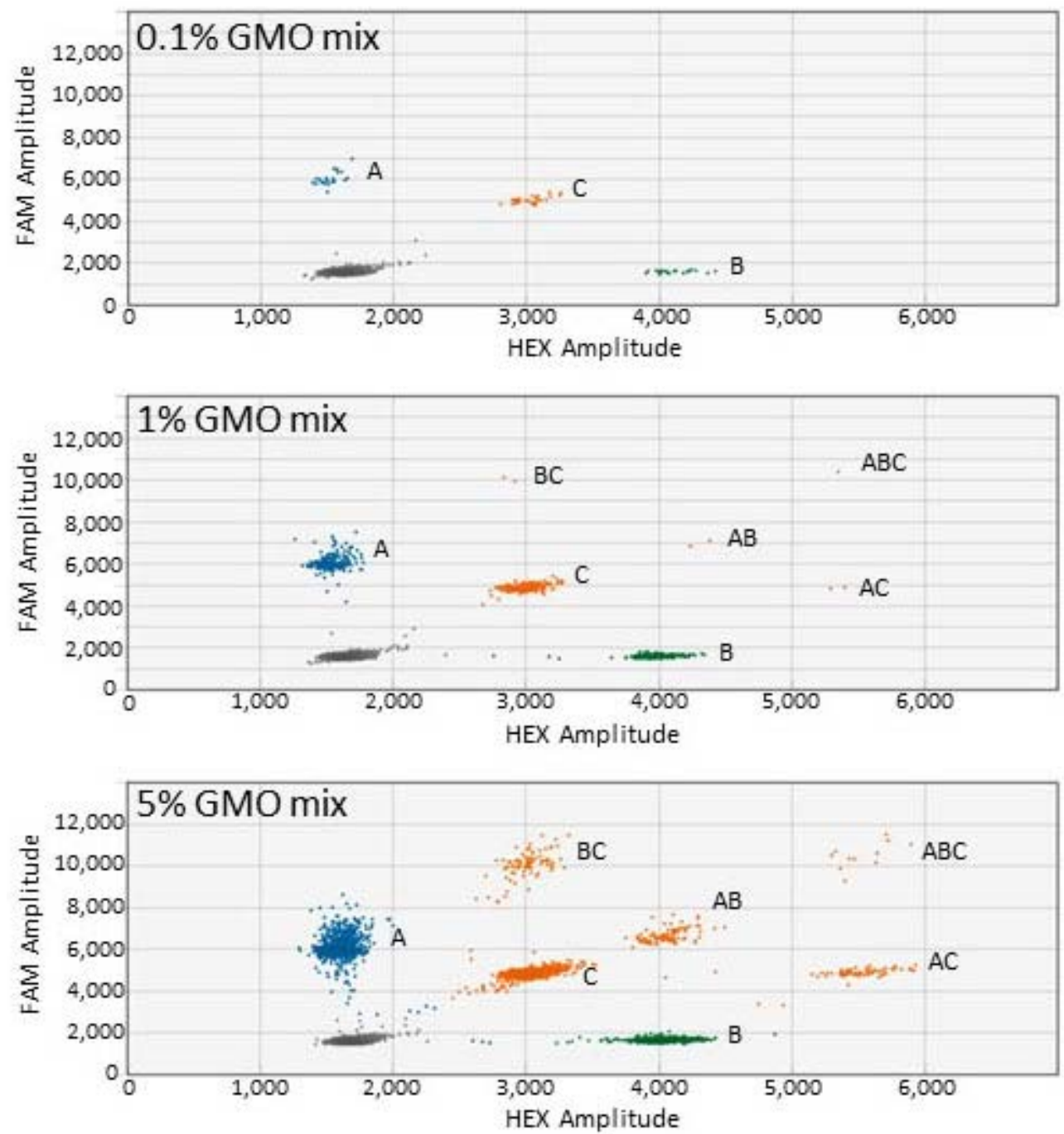

Figure 3. Droplet clusters generated for the canola triplex ddPCR assay (two-dimensional view). A = HCN92 (FAM); B = GT73 (HEX); C = MON88302 (FAM and HEX). The dark cluster represents negative droplets. 


\subsection{Detection of Four GM Events (Tetraplex ddPCR)}

Careful optimization of the probe concentrations was required for the tetraplex ddPCR assays. Different amounts of probe concentrations were tested in order to obtain clear separation of the different clusters. The tetraplex ddPCR assay results for four GM canola events (HCN92, GT73, OXY235, and MON88302) are shown in Table 4. Close to the expected results were achieved for the $0.1 \%, 1 \%$, and $5 \%$ GM canola samples. The tetraplex ddPCR for the GM soybean assay consisted of A2704, DP305423, DAS81419, and MON89788 events. Close to the expected results were achieved for three of the four GM events (Table 4). For the DP305423 GM soybean event, higher than expected results were obtained. The results for this event were also higher for the duplex and triplex ddPCR. A two-dimensional view of the separation of droplets for the 15 possible combinations for the tetraplex ddPCR soybean assay is provided in Figure 4. There was a clear separation of the negative and the 15 positive droplet clusters. Clear separation of droplet clusters was not obtained before optimization of probe concentrations (Figure 1). It was relatively easy and faster to identify the clusters with the QX Manager software.

Table 4. Experimental results for the tetraplex ddPCR assays for GM canola and soybean events.

\begin{tabular}{cccccc}
\hline \multirow{2}{*}{ Crop } & \multirow{2}{*}{ Tetraplex Events } & \multirow{2}{*}{ Event } & \multicolumn{3}{c}{ Experimental Results a } \\
\cline { 4 - 6 } & & & $\mathbf{0 . 1 \%}$ & $\mathbf{1 \%}$ & $\mathbf{5 \%}$ \\
\hline \multirow{2}{*}{ Canola } & GT73, MON88302, & GT73 & $0.11 \pm 0.02$ & $1.07 \pm 0.05$ & $5.01 \pm 0.19$ \\
& OXY235, and HCN92 & MON88302 & $0.12 \pm 0.02$ & $1.10 \pm 0.04$ & $5.07 \pm 0.18$ \\
& & OXY235 & $0.12 \pm 0.01$ & $1.26 \pm 0.10$ & $5.75 \pm 0.12$ \\
\multirow{5}{*}{ Soybean } & A2704, DP305423, & HCN92 & $0.10 \pm 0.03$ & $1.13 \pm 0.07$ & $5.06 \pm 0.05$ \\
& DAS81419, MON89788 & A2704 & $0.14 \pm 0.0$ & $1.31 \pm 0.13$ & $6.03 \pm 0.18$ \\
& & DAS305423 & $0.16 \pm 0.02$ & $1.50 \pm 0.08$ & $6.67 \pm 0.20$ \\
& & MON89788 & $0.11 \pm 0.01$ & $1.10 \pm 0.08$ & $4.74 \pm 0.20$ \\
& & & $0.13 \pm 0.03$ & $1.22 \pm 0.30$ & $5.00 \pm 0.17$ \\
\hline
\end{tabular}

average of three replications \pm standard deviation.

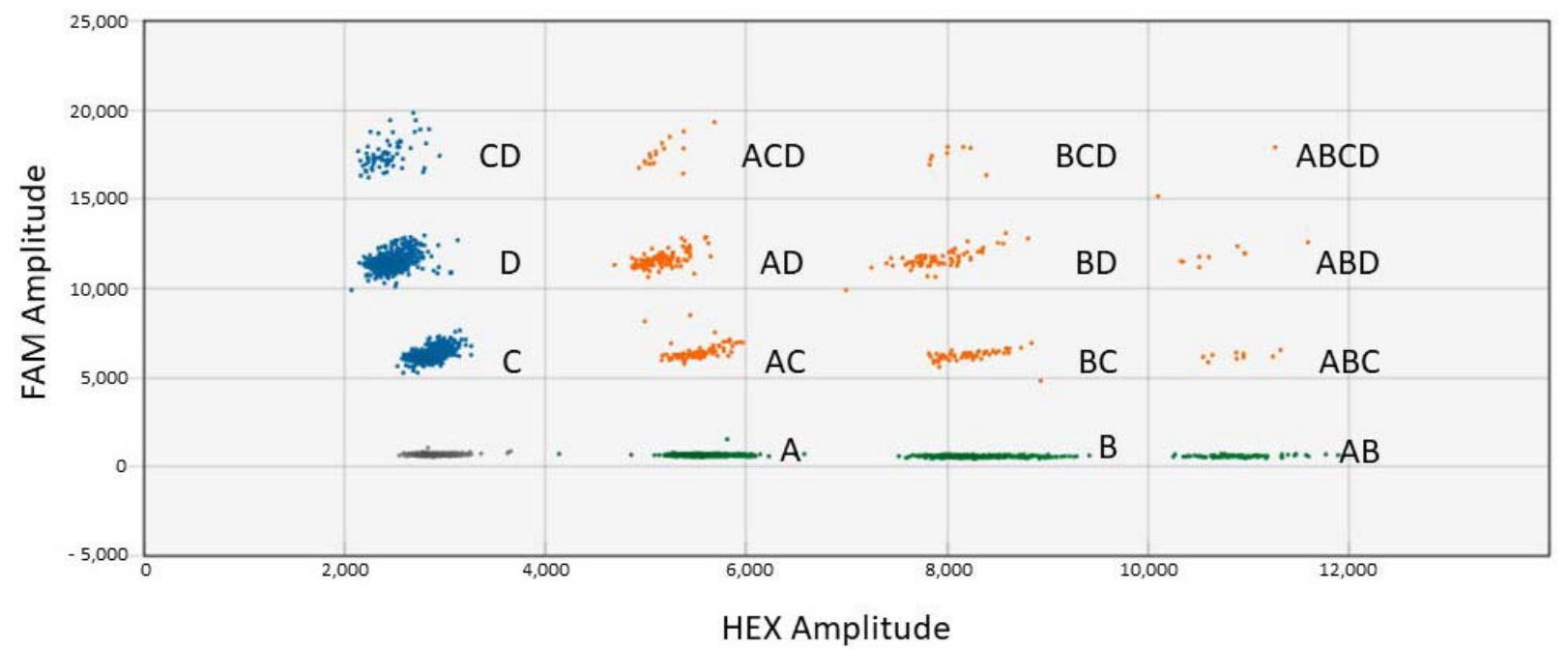

Figure 4. Droplet clusters generated for the soybean tetraplex ddPCR assay (two-dimensional view). A = DP305423 event (HEX); B = DAS81419 event (HEX); C = MON89788 event (FAM); and $\mathrm{D}=\mathrm{A} 2704$ event (FAM). The dark cluster represents negative droplets.

Overall, successful tetraplex ddPCR assays were developed for absolute quantification of GM canola and soybean events at $0.1 \%, 1 \%$, and $5 \%$ levels. Amplification was achieved for all samples at $0.1 \%$, which is the minimum required performance limit for the validation of quantitative methods [10]. The duplex, triplex, and tetraplex ddPCR canola and soybean assays described in this study will be applicable for other GM events. Optimization of 
the probe concentrations may be needed for cluster separation and successful multiplex ddPCR assay of other GM events.

\section{Conclusions}

In most of the reports of GM detection and quantification using $\mathrm{APCR}$, a duplex assay consisting of a GM event and a reference gene was used at the same time. However, it is important to increase the efficiency of GM event detection using multiplex ddPCR. The feasibility of the absolute quantification of two, three, and four GM events at the same time was investigated in this study. Optimization of the probe concentrations and labels was necessary for some of the assays in order to obtain successful multiplex ddPCR results. Absolute quantification of two, three, and four GM canola and soybean events was achieved using the QX200 ddPCR instrument at $0.1 \%, 1 \%$, and $5 \%$ levels. The developed multiplex ddPCR assays will help to enhance the efficiency of GM detection and quantification for canola and soybean events. The duplex, triplex, and tetraplex ddPCR canola and soybean assays described in this study are also applicable to the detection and quantification of other GM events.

Supplementary Materials: The following supporting information can be downloaded at: https: / /www.mdpi.com/article/10.3390/biology11020201/s1, Table S1: Primer and probe concentrations and probe labels used for duplex ddPCR assays, Table S2: Primer and probe concentrations and probe labels used for triplex ddPCR assays, Table S3: Primer and probe concentrations and probe labels used for tetraplex ddPCR assays.

Author Contributions: Conceptualization: T.D., S.J.L., M.E.; Methodology, M.E., S.-J.L.; Original draft preparation, T.D.; Review and editing, M.E., S.-J.L. All authors have read and agreed to the published version of the manuscript.

Funding: The research was funded by Canadian Grain Commission.

Institutional Review Board Statement: Not applicable.

Informed Consent Statement: Not applicable.

Data Availability Statement: Data is contained within the article or Supplementary Material.

Acknowledgments: Veronique Barthet, Program Manager of the Oilseeds Program of the Grain Research Laboratory of the Canadian Grain Commission is acknowledged for supply of seeds. WG Thompson \& Sons (Ontario, Canada) provided certified seeds of Colby and certified seeds of PS 2295 LL were obtained from Bayer Crop Science.

Conflicts of Interest: The authors declare no conflict of interest.

\section{References}

1. James, C. Global Status of Commercialized Biotech/GM Crops: International Service for Acquisition of Ari-Biotech Applications; ISAAA Brief 52; The International Service for the Acquisition of Agri-Biotech Applications (ISAAA): Manila, Philippines, 2016. Available online: https:/ / www.isaaa.org/resources/publications/briefs/52/executivesummary/default.asp (accessed on 17 January 2022).

2. European Commission. Regulation (EC) No. 1829/2003 of the European Parliament and of the Council of 22 September 2003 on genetically modified food and feed. Off. J. Eur. Union 2003, 268, 1-23.

3. Vigani, M.; Raimondi, V.; Olper, A. International trade and endogenous standards: The case of GMO regulations. World Trade Rev. 2012, 11, 415-437. [CrossRef]

4. Rosculete, E.; Bonciu, E.; Rosculete, C.A.; Teleanu, E. Detection and quantification of genetically modified soybean in some food and feed products. A case study on products available on Romanian market. Sustainability 2018, 10, 1325. [CrossRef]

5. Peng, C.; Zheng, M.; Ding, L.; Chen, X.; Wang, X.; Feng, X.; Wang, J.; Xu, J. Accurate detection and evaluation of the gene-editing frequency in plants using droplet digital PCR. Front. Plant Sci. 2020, 11, 610790. [CrossRef]

6. Cottenet, G.; Blancpain, C.; Sonnard, V.; Chuah, P.F. Development and validation of a multiplex real-time pCR method to simultaneously detect 47 targets for the identification of genetically modified organisms. Anal. Bioanal. Chem. 2013, 405, 6831-6844. [CrossRef]

7. Mano, J.; Hatano, S.; Nagatomi, Y.; Futo, S.; Takabatake, R.; Kitta, K. Highly sensitive GMO detection using real-time PCR with a large amount of DNA template: Single-laboratory validation. J. AOAC Int. 2018, 101, 507-514. [CrossRef] 
8. Peng, C.; Wang, P.; Xu, X.; Wang, X.; Wei, W.; Chen, X.; Xu, J. Development of a qualitative real-time PCR method to detect 19 targets for identification of genetically modified organisms. SpringerPlus 2016, 5, 889. [CrossRef]

9. Scholtens, I.M.J.; Kok, E.J.; Hougs, L.; Molenaar, B.; Thissen, J.T.N.M.; van der Voet, M. Increased efficacy for in-house validation of real-time PCR GMO detection methods. Anal. Bioanal. Chem. 2010, 396, 2213-2227. [CrossRef]

10. European Commission. EU Commission Regulation No. 619/2011. Laying down the methods of sampling and analysis for the official control of feed as regards presence of genetically modified material for which an authorisation procedure is pending or the authorisation of which has expired. Off. J. Eur. Union 2011, 166, 9-15. Available online: https://eur-lex.europa.eu/legalcontent/EN/TXT/PDF/?uri=CELEX:32011R0619\&from=EN (accessed on 4 January 2022).

11. Quan, P.L.; Sauzade, M.; Brouzes, E. dPCR: A technology review. Sensors 2018, 18, 1271. [CrossRef]

12. The dMIQE Group; Huggett, J.F. The digital MIQE guidelines update: Minimum information for publication of quantitative digital PCR experiments for 2020. Clin. Chem. 2020, 66, 1012-1029. [CrossRef] [PubMed]

13. Pinheiro, L.B.; O’Brien, H.; Druce, J.; Do, H.; Kay, P.; Daniels, M.; You, J.; Burke, D.; Griffiths, K.; Emslie, R. Interlaboratory reproducibility of droplet digital polymerase chain reaction using a new DNA reference material format. Anal. Chem. 2017, 89, 11243-11251. [CrossRef] [PubMed]

14. Whale, A.S.; Devonshire, A.S.; Karlin-Neumann, G.; Regan, J.; Javier, L.; Cowen, S.; Fernandez-Gonzalez, A.; Jones, J.M.; Redshaw, N.; Beck, J.; et al. International interlaboratory digital PCR study demonstrating high reproducibility for the measurement of a rare sequence variant. Anal. Chem. 2017, 89, 1724-1733. [CrossRef] [PubMed]

15. Iwobi, A.; Gerdes, L.; Busch, U.; Pecoraro, S. Droplet digital PCR for routine analysis of genetically modified foods (GMOs) -A comparison with real-time quantitative PCR. Food Control 2016, 69, 205-213. [CrossRef]

16. Nixon, G.; Garson, J.A.; Grant, P.; Nastouli, E.; Foy, C.A.; Huggett, J.F. Comparative study of sensitivity, linearity, and resistance to inhibition of digital and nondigital polymerase chain reaction and loop mediated isothermal amplification assays for quantification of human cytomegalovirus. Anal Chem. 2014, 86, 4387-4394. [CrossRef]

17. Zhao, Y.; Xia, Q.; Yin, Y.; Wang, Z. Comparison of droplet digital PCR and quantitative PCR assays for quantitative detection of Xanthomonas citri Subsp. citri. PLoS ONE 2016, 11, e0159004. [CrossRef]

18. Demeke, T.; Dobnik, D. Critical assessment of digital PCR for the detection and quantification of genetically modified organisms. Anal. Bioanal. Chem. 2018, 410, 4039-4050. [CrossRef]

19. Whale, A.S.; Cowen, S.; Foy, C.A.; Huggett, J.F. Methods for applying accurate Digital PCR analysis on Low Copy DNA Samples. PLoS ONE 2013, 8, e58177. [CrossRef]

20. Collier, R.; Dasgupta, K.; Xing, Y.P.; Hernandez, B.T.; Shao, M.; Rohozinski, D.; Kovak, E.; Lin, J.; de Oliveira, M.L.P.; Stover, E.; et al. Accurate measurement of transgene copy number in crop plants using droplet digital PCR. Plant J. 2017, 90, 1014-1025. [CrossRef]

21. Long, L.; Yan, W.; He, Y.; Dong, L.; Xing, Z.; Li, C.; Xia, W.; Li, F. Development of a duplex digital PCR method to quantify five genetically modified soybean events. Food Anal. Methods 2021, 7, 8601. [CrossRef]

22. Morisset, D.; Štebih, D.; Milavec, M.; Gruden, K.; Žel, J. Quantitative analysis of food and feed samples with droplet digital PCR. PLOS ONE 2013, 8, e62583. [CrossRef]

23. Zhong, Q.; Bhattacharya, S.; Kotsopoulos, S.; Olson, J.; Taly, V.; Griffiths, A.D.; Link, D.R.; Larson, J.W. Multiplex digital PCR: Breaking the one target per color barrier of quantitative PCR. Lab Chip 2011, 11, 2167-2174. [CrossRef] [PubMed]

24. Dobnik, D.; Štebih, D.; Blejec, A.; Morisset, D.; Žel, J. Multiplex quantification of four DNA targets in one reaction with Bio-Rad droplet digital PCR system for GMO detection. Sci. Rep. 2016, 6, 35451. [CrossRef] [PubMed]

25. Whale, A.S.; Huggett, J.F.; Tzonev, S. Fundamentals of multiplexing with digital PCR. Biomol. Detect. Quantif. 2016, 10, 15-23. [CrossRef]

26. The International Service for the Acquisition of Agri-Biotech Applications (ISAAA). Global Status of Commercialized Biotech/GM Crops; ISAAA Brief 54; The International Service for the Acquisition of Agri-Biotech Applications: Manila, Philippines, 2018. Available online: https:/ / www.isaaa.org/resources/publications/briefs/54/default.asp (accessed on 10 January 2020).

27. Demeke, T.; Eng, M.; Holigroski, M.; Lee, S.-J. Effect of amount of DNA on Digital PCR assessment of genetically engineered canola and soybean events. Food Anal. Methods 2021, 14, 372-379. [CrossRef]

28. Henderson, N.; Harmon, M.; Zhong, C.X. PCR-based detection and quantification of a transgenic glyphosate-tolerant canola using a novel reference gene system. Food Anal. Methods 2016, 9, 353-361. [CrossRef]

29. European Union Reference Laboratory for Genetically Modified Food (EURL-GMFF). Event-Specific Method for Quantification of Soybean Line 40-3-2 Using Real-Time PCR; Joint Research Centre: Ispra, Italy, 2009. Available online: https:/ / gmo-crl.jrc.ec.europa. eu/summaries/40-3-2_validated_Method.pdf (accessed on 10 January 2022).

30. European Reference Laboratory for GM Food and Feed (EURL-GMFF). Method Validations. Available online: https://gmo-crl. jrc.ec.europa.eu/method-validations (accessed on 10 January 2022).

31. Wu, G.; Wu, Y.; Xiao, L.; Lu, C. Event-specific qualitative and quantitative PCR methods for the detection of genetically modified rapeseed Oxy-235. Transgenic Res. 2008, 17, 851-862. [CrossRef]

32. European Reference Laboratory for GM Food and Feed (EURL-GMFF). Event-Specific Method for the Quantification of Soybean Event DP305423-1 Using Real-Time PCR; Joint Research Centre: Ispra, Italy, 2009. Available online: https://gmo-crl.jrc.ec.europa.eu/ summaries/CRLVL0707VP\%20Corr2\%20EURL\%20web.pdf (accessed on 8 January 2022). 